\title{
Colo-Colonic Intussusception Caused by a Submucosal Lipoma
}

\section{Case Report and Review of the Literature}

\author{
B.A. Twigt S.K. Nagesser D.J.A. Sonneveld \\ Department of Surgery, Diakonessenhuis, Utrecht, The Netherlands
}

\section{Key Words}

Lipoma - Intussusception · Submucosal · Colonic lipoma - Intestinal obstruction

\begin{abstract}
Adult intussusception is a rare clinical presentation and often not considered clinically in the differential diagnosis of adult patients with vague abdominal complaints. A 44-yearold woman visited our emergency department with sudden onset of intermittent abdominal pain. Diagnostic imaging revealed an intussusception caused by a submucosal lipoma of the sigmoid. A laparotomy was performed and the diagnosis was proven by histological examination. Submucosal lipomas are usually asymptomatic but may cause bleeding, obstruction, intussusception, or abdominal pain and thus mimic a malignancy. Surgical excision is indicated for symptomatic cases.
\end{abstract}

\section{Introduction}

Colo-colonic intussusception in adults is a rare entity. We report a case of adult intussusception caused by a submucosal lipoma in the sigmoid colon, review the literature and discuss the optimal management.

\section{Case Report}

A 44-year-old woman visited our emergency room with sudden onset of intermittent abdominal cramps. She was nauseous and had had rectal blood loss for two days. Physical examination showed a tender palpable mass in the left lower abdominal quadrant. Rectal examination showed little blood on the glove. Laboratory examination revealed no abnormalities. Ultrasound showed a target lesion in the left lower abdominal quadrant. A consecutive CT scan demonstrated a clear intussusception of the sigmoid (fig. 1). Since the clinical presentation was that of an imminent ileus a laparotomy was performed. The intussusception was found in the sigmoid (fig. 2, fig. 4), and en-bloc resection was performed with end-to-end anastomosis. The postoperative course was uneventful and the patient was 
discharged on day six postoperative. The pathology report revealed a $6 \mathrm{~cm}$ submucosal lipoma of the sigmoid with reactive changes (fig. 3). Postoperative colonoscopy showed no further abnormalities.

\section{Discussion}

Adult intussusception is a rare clinical presentation. Unlike in children, intussusception in adults is associated with an identifiable etiology in $90 \%$ of cases, the socalled leading point [1]. Consequently, non-operative reduction is not the treatment of choice in adults as it is in children. Colo-colonic intussusception is likely to have a malignant etiology (50-60\%). This reflects the greater prevalence of malignant tumors (adenocarcinoma and lymphoma) in the colon compared with the small bowel. Benign lesions constitute about $30 \%$ and include neoplasms such as lipoma, adenomatous polyp, neurofibroma, hemagioma and leiomyoma. Postoperative causes might consist of adhesions, motility disorders, presence of suture materials or an anastomosis. Idiopathic intussusception occurs less often than in the small bowel and is a rare entity.

Although lipoma represents the most common benign tumor of the colon, it is a relatively rare cause of gastrointestinal symptoms. Postmortem series have shown that up to $4 \%$ of gastrointestinal tumors are lipomas [2]. In the majority of the patients its appearance is isolated, while in approximately $10 \%$ there are multiple lipomas.

Preferential location is the right sided hemi colon, accounting for nearly $90 \%$ of cases $[3$, 4]. Most of the time the lipoma is situated submucosally, but it can also be subserosal, originating from an appendix epiploica. The size may vary from 0.5 to as much as $10 \mathrm{~cm}$. Small lipomas are usually asymptomatic and are found incidentally during colonoscopy. Large lipomas are usually symptomatic and may mimic clinical signs almost identical to malignant tumors. They may cause bleeding, obstruction or intussusception. Symptoms are often chronic, with intermittent abdominal pain being the main symptom. Unlike intussusception in children, an acute onset bowel obstruction is a rare presentation in adults.

Intussusception is often not considered clinically in the differential diagnosis of adult patients with vague abdominal complaints. With the widespread use of CT and increasing numbers of colonoscopies in the evaluation of non-specific abdominal pain, nowadays the diagnosis is most often made by the radiologist or gastroenterologist.

While the appearance of intussusception is characteristic on CT, its etiology usually cannot be established. On CT a lipoma has a uniform appearance with fat-equivalent density and a smooth border. However, even if the radiological image may suggest strong evidence for the existence of a lipoma, radiologists will often also mention other more malignant options in their differential diagnosis.

Colonoscopy may show some characteristic findings in patients with a submucosal lipoma: a yellow submucosal mass with marked elasticity, easily demonstrated by compressing and releasing the tissue with a closed biopsy forceps. This phenomenon is known as the cushion or pillow sign. Furthermore, fat tissue may protrude through the biopsy site, this is called the naked fat sign $[5,6]$. Nevertheless, the colonoscopic image may be deceptive, presenting with hemorrhage, necrosis and mucosal ulceration [7].

Submucosal lipomas only need resection if they are symptomatic. Small lipomas $(<2$ $\mathrm{cm}$ ) can be safely removed endoscopically $[8,9]$. Larger lipomas, however, are unreliable to endoscopic removal. The risk of perforation or hemorrhage is increased because the fatty tissue is an inefficient conductor for electronic current, especially when the lesion is sessile [10]. Therefore the definitive treatment for complete removal of bigger 
symptomatic lipomas is surgical resection. Both laparoscopic and open resections have been described $[11,12]$. En-bloc resection of the effected intestine should be the surgical treatment of choice in the majority of cases due to the high percentage of malignancy. If the preoperative diagnosis of colon lipoma can be made correctly, extent of surgery may be appropriately limited.

\section{Conclusion}

The most important factor for establishing the diagnosis of intussusception caused by a submucosal lipoma is awareness of the possibility, especially in adult patients with abdominal symptoms and prior episodes of partial intestinal obstruction. Submucosal lipomas are usually asymptomatic but may cause bleeding, obstruction, intussusception, or abdominal pain. Differential diagnosis includes malignancy, diverticulosis, adenomatous polyps and previous anastomosis. CT is the examination of choice [13].

Fig. 1. CT of the abdomen. Intussusception of a mass in the sigmoid. Density resembles fat tissue.

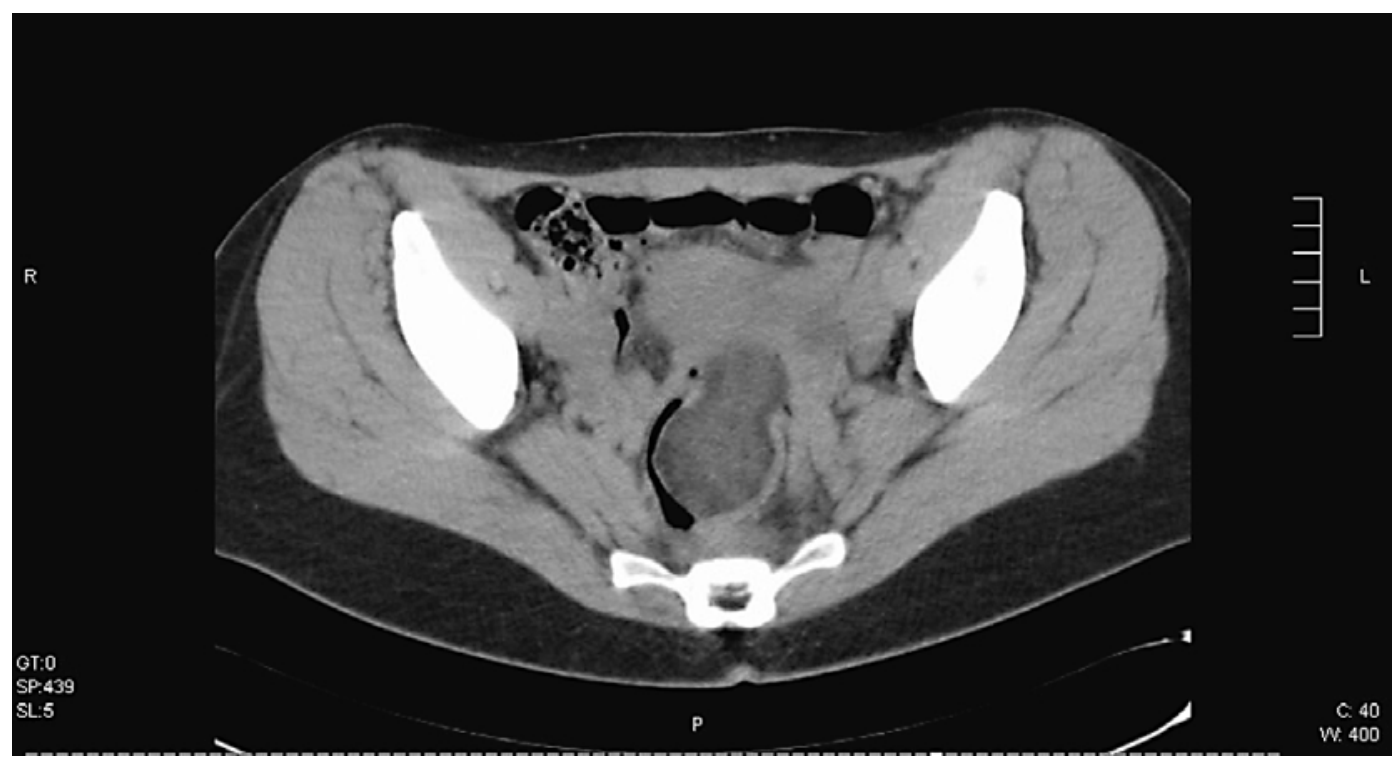


Fig. 2. Intraoperative finding. Intussusception of the sigmoid.

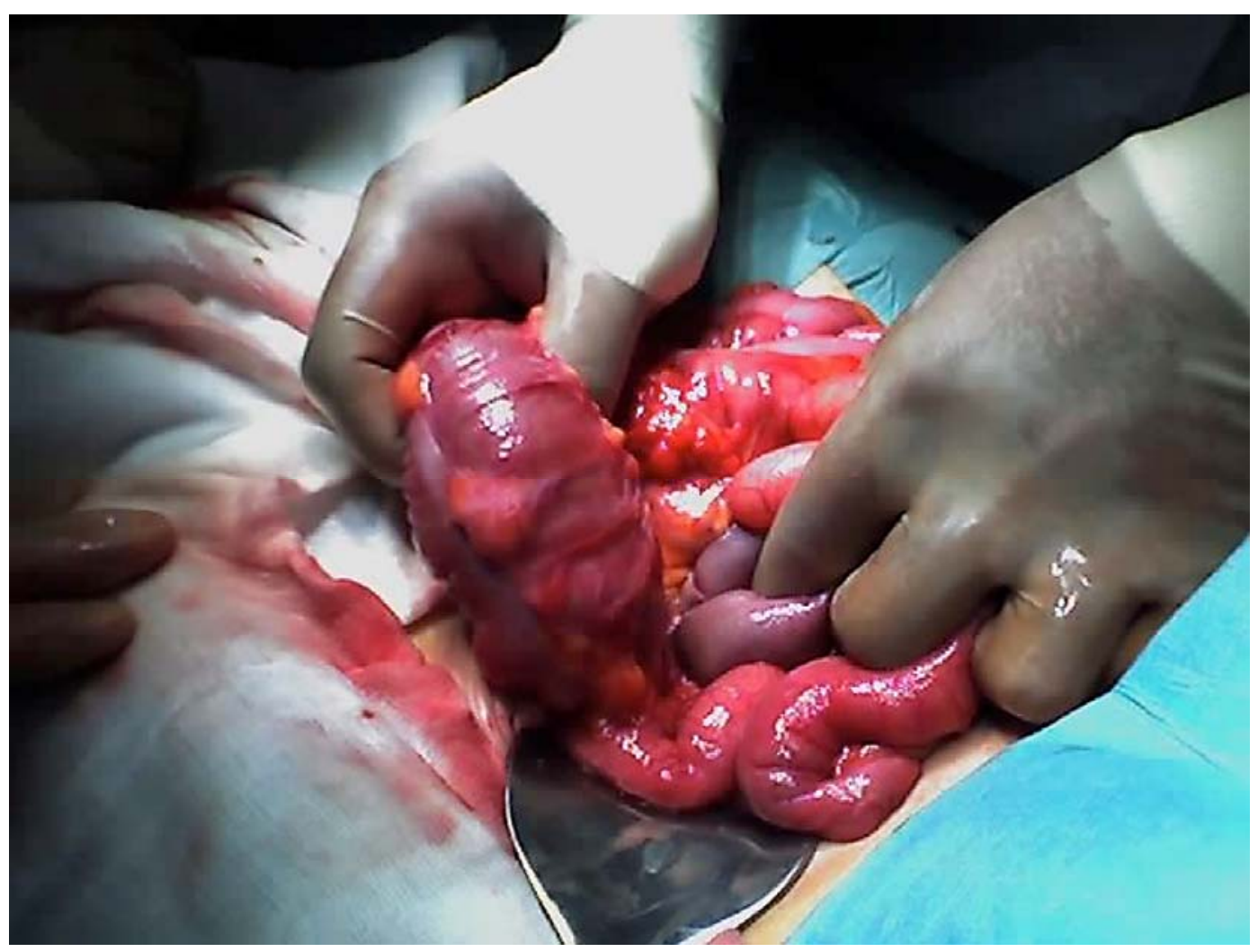


Fig. 3. Histopathological section showed fat cells underlining the mucosa of the colon.

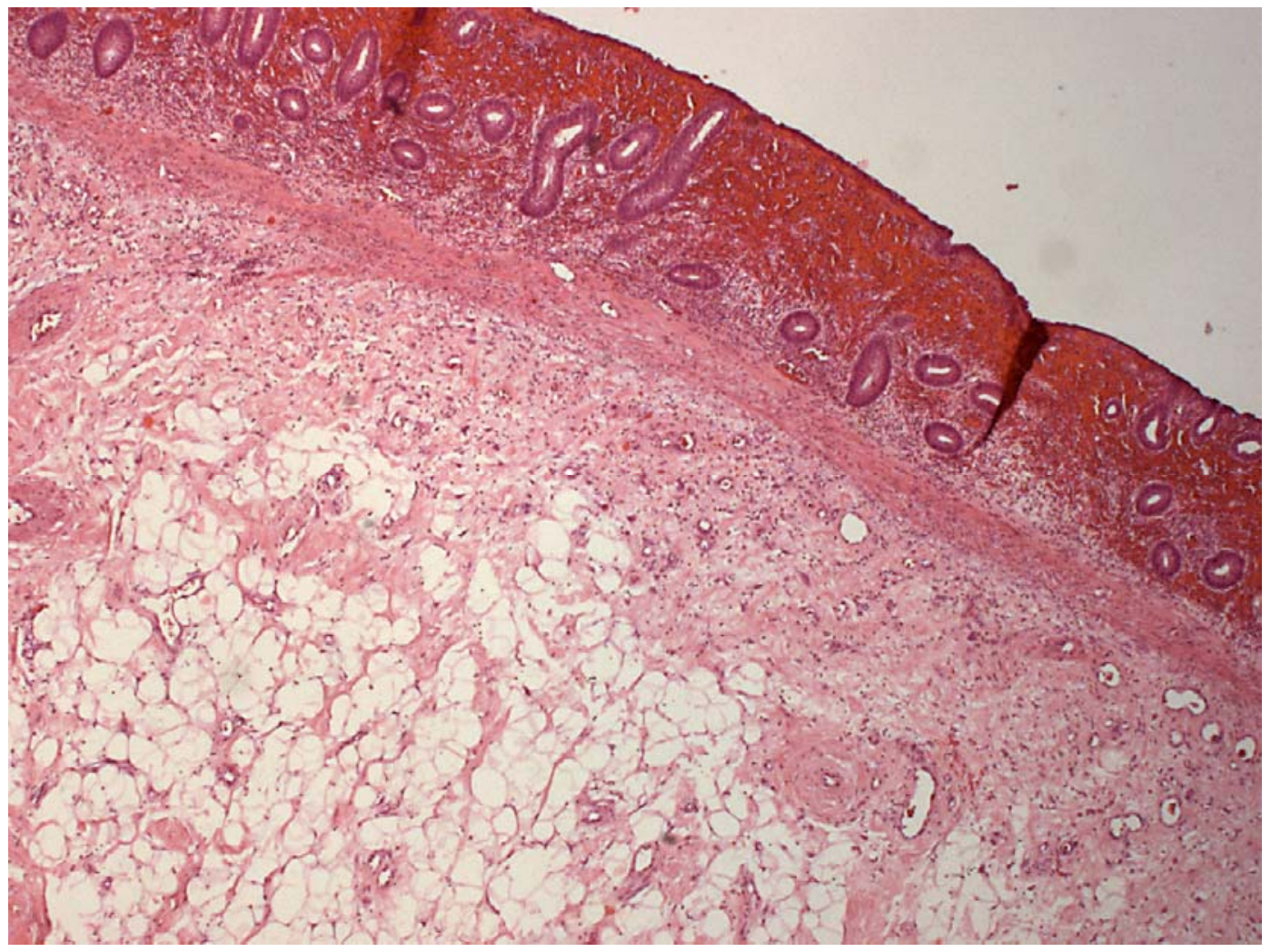

Fig. 4. Intraoperative photo of colo-colonic intussusception. An instrument is introduced in the false lumen of the intussusception.

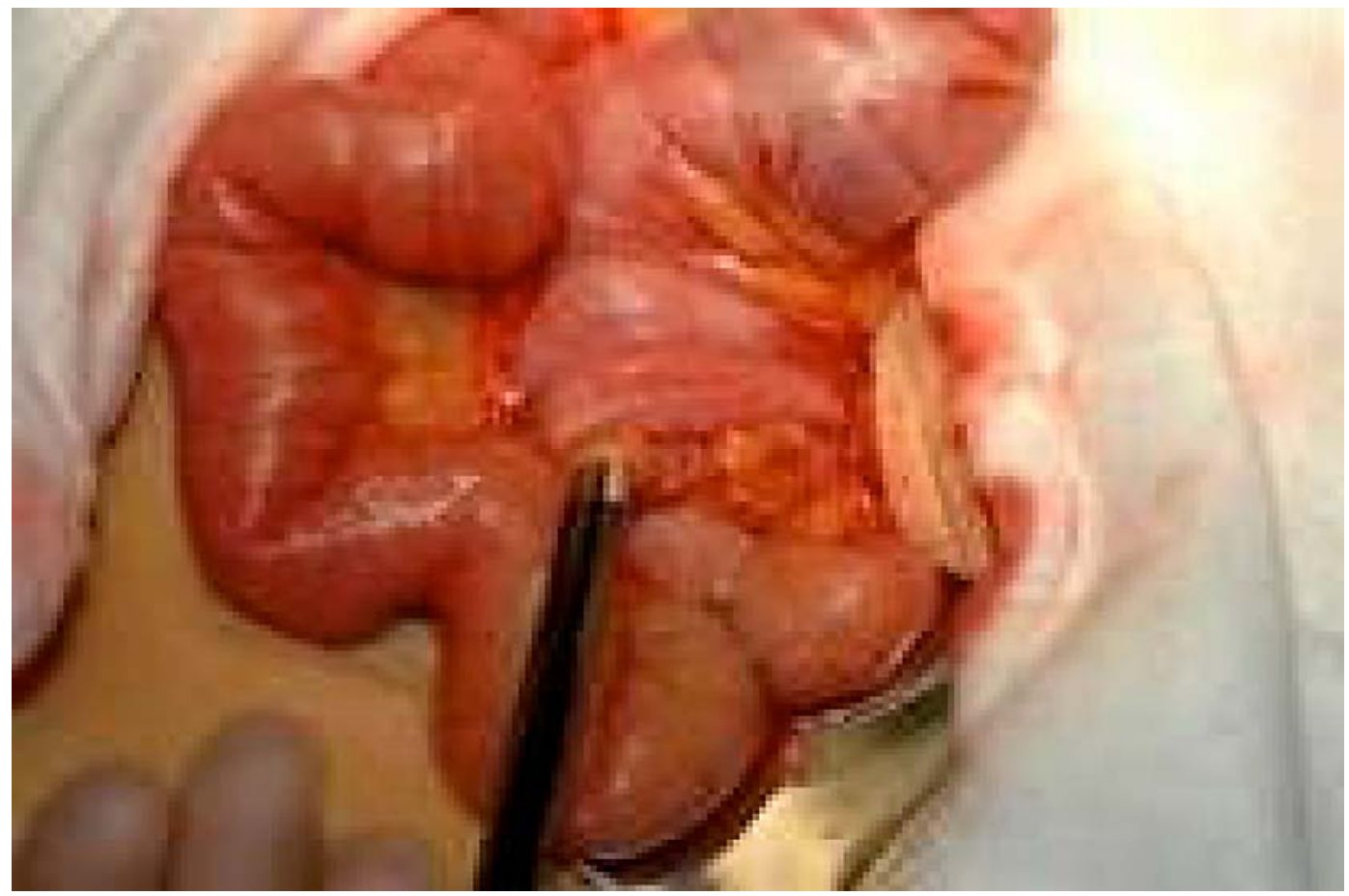




\section{References}

1 Alkim C, Sasmaz N, Alkim H, Caglikuleci M, Turhan N: Sonographic findings in intussusception caused by a lipoma in the muscular layer of the colon. J Clin Ultrasound 2001;29:298-301.

2 Mayo CW, Pagtalunan RJ, Brown DJ: Lipoma of the alimentary tract. Surgery 1963;53:598-603.

3 Zhang H, Cong JC, Chen CS, Qiao L, Liu EQ: Submucous colon lipoma: A case report and review of the literature. World J Gastoenterol 2005;11:3167-3169.

-4 El-Khalil T, Mourad F, Uthman S: Sigmoid lipoma mimicking carcinoma: Case report with review of diagnosis and managment. Gastrointest Endosc 2000;51:495-496.

5 Notaro JR, Masser PA: Annular colon lipoma: A case report and review of the literature. Surgery 1991;110:570-572.

6 Ryan J, Martin JE, Pollock DJ: Fatty tumours of the large intestine: A clinicopathological review of 13 cases. Br J Surg 1989;76:793-796.

7 Meghoo C, Cook P, McDonough C, Bowser LK, Waddell BE: Large colonic lipoma with mucosal ulceration mimicking carcinom. Gastrointest Endosc 2003;58:468-470.

8 Yu JP, Luo HS, Wang XZ: Endoscopic treatment of submucosal lesions of the gastro-intestinal tract. Endoscopy 1992;24:190-193.

>9 Pfeil SA, Weaver MG, Abdul-Karim FW, Yang P: Colonic lipomas: Outcome of endoscopic removal. Gastrointestest Endosc 1990;36:435-438.

10 Chase MP, Yarze JC: 'Giant' colon lipoma - to attempt endoscopic resection or not? Am J Gastroenterol 2000;95:2143-2144.

-11 Yu HG, Ding YM, Tan S, Luo HS, Yu JP: A safe and efficient strategy for endoscopic resection of large, gastrointestinal lipoma. Surg Endosc 2007;21:265269.

12 Nakagoe T, Sawai T, Tsuji T, Tanaka K, Nanashima A, Shibasaki S, Yamaguchi H, Yasutake T: Minilaparotomy approach for removal of a large colonic lipoma: report of two cases. Surg Today 2004;34:72-75.

13 Gehlen JMLG, van Berlo CLH, van der Horst F, Nijhuis PHA: Unexplained vague abdominal complaints in adults: Indication for CT in case of suspected intussusception. Ned Tijdschrift Geneeskd 2003;147:681-685. 